Article

\title{
Inclusion of Life Cycle Thinking in a Sustainability-Oriented Consumer's Typology: A Proposed Methodology and an Assessment Tool
}

\author{
Anna Lewandowska ${ }^{1, *}$, Joanna Witczak ${ }^{1}$, Pasquale Giungato ${ }^{2}$ (D), Christian Dierks ${ }^{3}$, \\ Przemyslaw Kurczewski ${ }^{4}$ and Katarzyna Pawlak-Lemanska ${ }^{1}$ \\ 1 Faculty of Commodity Science, Poznan University of Economics and Business, 61-875 Poznan, Poland; \\ joanna.witczak@ue.poznan.pl (J.W.); Katarzyna.Pawlak-Lemanska@ue.poznan.pl (K.P.-L.) \\ 2 Chemistry Department, University of Bari Aldo Moro, Taranto district-via Alcide de Gasperi, \\ 74123 Taranto, Italy; pasquale.giungato@uniba.it \\ 3 Fraunhofer Project Group Materials Recycling and Resource Strategies, Brentanostrasse 2a, \\ 63755 Alzenau, Germany; c.dierks@protonmail.com \\ 4 Faculty of Machines and Transportation, Poznan University of Technology, Piotrowo 3, \\ 60-965 Poznan, Poland; przemyslaw.kurczewski@put.poznan.pl \\ * Correspondence: anna.lewandowska@ue.poznan.pl; Tel.: +48-61-854-3121
}

Received: 8 April 2018; Accepted: 29 May 2018; Published: 1 June 2018

\begin{abstract}
Characterizing consumers in terms of their propensity to practice sustainable consumption represents an interesting research challenge in which a crucial role is played by the questionnaire in terms of its structure and classification criteria. Various classification rules have been proposed in the literature, which can be used to identify consumer types and signify their propensity to practice the principles of sustainable development in daily life. In this paper, we based our approach in designing a classification tool on a combination of two elements: the concept of voluntary simplicity as a pillar for consumer characteristics and the idea of assessing consumers by using filters, in a modified form introducing many new aspects of life-cycle thinking. The tool proposed provides insight into the relationship between the consumer's typology and behavior during purchasing decisions in daily life. The main function of the proposed tool is to assign respondents to one of the proposed consumer types distinguished and characterized in terms of many aspects of life cycle thinking. A pilot survey has been performed in order to verify the proposed tool, and the survey results have been presented in the paper, as well.
\end{abstract}

Keywords: consumer classification; voluntary simplicity; life cycle thinking; purchasing criteria; sustainability

\section{Introduction}

Sustainability is now a well-defined concept, having come a long way from being a theoretical definition provided by the Brundtland report [1] to becoming a widely-recognized and internationally-accepted roadmap for long-term strategies [2] implemented on a global macro-scale $[3,4]$ as well as a micro-scale. On the micro-scale, numerous initiatives are being developed for small and medium enterprises [5]: to evaluate the consciousness of consumers regarding sustainable consumption taking into account the environmental, social and economic dimensions of sustainability [6]; to study the sustainability of supply networks in small and medium-sized enterprises [7]; to evaluate companies' commitments in the area of sustainability [8,9]; to promote collaboration between industry and academia within the context of sustainability science [10]; as well as implementing new bachelor's degrees in environmental and engineering sciences to spread 
sustainable development throughout higher education locally [11] and worldwide [12]. Sustainable development is defined as "development that meets the needs of the present without compromising the ability of future generations to meet their own needs" [13], but implementing sustainable production and consumption patterns into real life is one of the most serious challenges for modern economies. Responsible consumption and production is one of the seventeen Sustainable Development Goals (SDGs) introduced on 25 September 2015 by the United Nations [14]. Achieving sustainable management and efficient use of natural resources is one of the highly desirable objectives. The need to decrease the material footprint, which measures the amount of raw materials extracted to meet the final domestic consumption demand of a country, is great. This is especially important in developed regions, where the material footprint per capita far exceeds that of the developing ones. In fact, there is a strong necessity to involve all countries in taking action. This need is clearly seen when the domestic material consumption (DMC) per unit of GDP is taken into consideration. From 2000-2010, the amount of material used in production, the amount of resources required to produce a unit of output, decreased worldwide except for in a few regions. An increase occurred in North Africa, as well as East, West and South-East Asia due to global shifts, evolving manufacturing and the rapid industrialization that followed. As a result, instead of a global decrease, DMC increased globally from $1.2 \mathrm{~kg}-1.3 \mathrm{~kg}$ per unit of GDP. Thus, managing to use fewer resources per unit of production and by institutional actors setting effective limits, as ceilings on greenhouse gas emissions or correcting prices for environmental externalities, are crucial to making sure that people account for the right social and environmental effects and costs in their private decisions [15]. The ordinary choices of individuals as consumers and producers have huge effects, as they occur on a massive scale; however, at least partially, these decisions do not necessarily have to result from voluntary frugality [16]. In environmental sciences, it is referred to as "destruction by insignificant increments" or "the tyranny of small decisions" to reflect the potential for exerting anthropic pressure [17]. On the other hand, consumer power, if directed correctly, could be able to make a "construction" by insignificant increments and to constitute a basis for conditioning the imperative of sustainability in everyday life. In this context, a vital question is what "everyday sustainability" means. Sustainability itself is a complex and multicomponent concept founded on the assumption that meeting human needs and achieving economic development should be made by ensuring a balance between economic, social and environmental systems. These elements are strongly interconnected and together are all crucial. Sustainable and equitable economic growth can contribute to alleviating poverty, reducing inequalities, raising standards of living for individuals and societies, promoting the integrated and sustainable management of natural resources and making environmental protection obligatory. Thus, sustainable development is based on all the above-mentioned efforts towards building an inclusive, sustainable and resilient future. Sustainability can be considered as the ability to find a compromise in difficult decision-making situations driven by various, often contradictory, criteria. Both sides of the market (supply and demand) should be ready to implement sustainability-oriented thinking into daily life. However, consumers can stimulate producers to incorporate sustainability into a product's characteristics, and analyzing consumer preferences plays an important role for producers and is often used as a basis for product assessment and improvement [18].

Several authors suggest that for sustainable development to occur, consumption practices must be changed from overconsumption to being globally responsible and based on lower levels of consumption [19-24]. This is more and more important especially in the context of increased pressure on the environment caused by many economies around the world despite the existence of cleaner and more efficient production technologies. The process is known as "relative decoupling". It refers to a decline in the ecological intensity per unit of economic output, but not necessarily a decline in absolute terms, because impacts may still increase due to increasing numbers of goods being produced, exchanged and consumed as a result of growing economies [25].

A really popular practice that has been increasing over many years is consumers considering the pro-environmental attributes of the products in their buying decisions $[21,26]$. 
Environmentally-responsible consumers are greatly concerned with the environment-related attributes of purchased goods. There is a positive relationship between a consumer's environmental attitudes and the likelihood of assuming environmentally-friendly behavior [27]. Sustainability and mindfulness of the natural environment are of the utmost importance to such consumers [28,29]. A conscious reduction of consumption could also mean adopting simpler living habits. This lifestyle is called voluntary simplicity (VS), and it complies with the requirements of sustainable consumption due to its main principles: an economically sustainable future, balanced relationships inside societies and a particular concern for environmental protection [30].

The most significant increase in academic interest in simple living was noted in Western societies in the 1970s and then later in the 1990s [29]. According to Elgin and Mitchell (1977) [31], the essence of voluntary simplicity is "living in a way that is outwardly simple and inwardly rich". As the authors stressed, this way of living is not new and can be rooted in the very distant past (e.g., the legendary frugality and self-reliance of the Puritans; in the teachings and social philosophy of a number of spiritual leaders such as Jesus and Gandhi) [31]. Iwata [32] described VS as a lifestyle of low consumption that includes low material dependency. As Roubanis noted [33], Iwata's definition embraces many aspects such as adherence to material simplicity, a preference for smaller items on the human scale, the espousal of an ideology reflecting ecological responsibility, the observance of a cautious attitude in shopping and a tendency to buy long-lasting items. Both Iwata and Roubanis performed surveys aimed at determining the levels of environmentally-responsible consumption and voluntary simplicity among students. Iwata [32] surveyed students attending a women's college in Japan, while Roubanis did similar research focused on students attending a U.S. college [33]. In the literature, there are many more examples of research focused on measuring voluntary simplicity in different societies. Kala et al. [34] did a survey among Czech households voluntarily reducing consumption, and they analyzed the results in a post-socialist context. Zavestoski [35] and Huneke [23] looked at this phenomenon as practiced in the United States. Shaw and Newholm [36] did similar research in the United Kingdom. Two examples of research in Turkey have been found as done by and Erdoğmuş and Karapınar [37] and Sertoğlu et al. [38]. Furthermore, an example of a survey in Poland [29] can be mentioned. It was done by Burgiel et al. and included two qualitative research projects using individual in-depth interviews that were conducted in the years 2013 and 2014. The authors concluded that Poles are presumably not yet ready to consciously and voluntarily limit their consumption [29].

A main goal of the paper is to present the results of the research aimed at developing a tool to be used for quick identification of respondents' environmental awareness. The idea of voluntary simplicity has been used as a starting point for establishing two pillars of the tool: a consumer typology and a questionnaire. In addition to aspects related to the consumption's reduction and dematerialization, some references to life cycle thinking (LCT) have also been included. Although the tool was originally designed for supporting research focused on assessing the communication effectiveness of life cycle-based environmental labelling [39], it can be recognized as a universal instrument and considered to be applied in any case where it is expected to obtain quick feedback on consumer environmental awareness. An advantage of the tool is the lack of the need for a face-to-face contact with the surveyed respondents, as the questionnaire can be filled out remotely.

\section{Materials and Methods}

\subsection{Methodological Background}

Many examples of consumer typology can be found in the literature in which the main classification criterion is the extent to which consumers include environmental- or sustainability-oriented aspects in purchasing decisions and/or daily choices [40-44]. According to these approaches, the consumers can be attributed with colors (shades of green, grey) or unique names (e.g., translators/exceptors/selectors) used to reflect the differences between them. The typology can be focused more on purchase decision-making or can be scoped more broadly to include choices made 
in ordinary life [41]. In the approach presented here, a starting point for establishing the consumer typology was the already mentioned concept of voluntary simplicity $[31,45,46]$ developed by the Simplicity Institute [47] and used for similar purposes by several authors [48-50]. Although embedded in a consumerist society characterized by a consumption-oriented lifestyle, there are individuals who deliberately refrain from excessive consumption [51]. They do not relate to individuals who restrict their consumption due to financial scarcity as they are financially well-off [23,35]; and they do not reduce their working hours and thereby income [52], but consciously reduce their consumption of goods to less than what they can afford for ethical reasons [53] and consume in ecologically-responsible ways [36]. The experience of co-housing [54], urban micro-wind power generation [55] and rural-urban squatting in Barcelona (Barcelona, Spain) [56] demonstrate that de-growth could be a collective life choice, the outcome of a general transition towards a more democratic and autonomous social and political organization [56]. Acceptance of economic de-growth would be facilitated if the emphasis on people's material achievements and aspirations were reduced [57]. Modern marketing builds symbolic associations between products and the psychological states of consumers, causing feelings of inadequacy, aspiration or expectation and creating a sense of inadequacy that the product could attenuate [58]; but for some, the values of moderation and frugality become central to their new sense of self [59]. Although aimed at a reduction of economic growth and the promotion of responsible consumption and voluntary simplicity as alternatives to consumerism, de-growth movements that initially faced systematic discrimination [60] are nowadays collecting a great following. In Germany, voluntary simplicity represents a remarkable segment (14.4\%) and is an interesting target group for both green products, durable products and sharing products, which all meet the need for lower consumption [61]. The reasons for these choices could be an awareness that environmental sustainability most probably cannot be attained with constantly growing production levels (measured by national income), but instead by a broad acceptance of a de-growth in production, bringing attainment of this goal within reach [62]. They consider physical capping of resources the only possible strategy to realize an end-to-growth policy, although it is capable of meeting environmental objectives, but implies significant social tensions and hardships; the opposite vision with respect to the majority of claims by schools of economics in which the central factor for social, economic, political and environmental progress is economic growth, assumed to create wealth and provide the necessary means for social and environmental purposes [63]. In our paper, we based our approach on a combination of the two aforementioned elements: the concept of voluntary simplicity as a pillar for consumer characteristics and the idea of assessing consumers by using filters. As mentioned earlier, the conception of VS is not new and has been used many times by different researchers to survey consumers. Furthermore, the idea of using sources of information connected with the voluntary simplicity concept has already been used by Oates et al. [48]. In our approach, we developed and used an electronic questionnaire closely integrated with the scoring system based on a unique method to generate the answers. For the purposes of our research, a special tool was designed to classify the surveyed respondents into one of the pre-defined consumer types based on their responses in the questionnaire. The questionnaire was divided into nine areas in order to reflect the following aspects of voluntary simplicity: material simplicity, a tendency to buy long-lasting items and to extend the durability of products, the inclusion of environmental and social aspects in shopping criteria and a tendency towards long-term thinking. Additionally, questions about the environmental performance of products and its importance in different life cycle stages were included. A new aspect provided by our case study is also the possibility of making the consumer classification individually for each part of the questionnaire, which makes it possible for the identification of potential differences in consumer attitudes depending on the issue analyzed (reflected by the questionnaire parts). The approach used in our research can be characterized by the following features:

- Complexity: Consumers are evaluated based on their preferences and decisions related to nine areas: purchasing criteria (PC), mode of decision-making (MDM), sources of general information 
about products (SGI), sources of environmental information about products (SEI), lifestyle (LS), thinking perspective (TP) and life cycle thinking (LCT) [64];

- Multi-criteria: The classification is based on information related to environmental, social and economic aspects. It considers issues regarding the value system, sense of responsibility and general way of prioritizing environmental problems, making it possible to classify consumers into one of three "archetypes" based on perspectives; individualists, hierarchists and egalitarians [65]; from the original five theoretical classes [66];

- Life cycle thinking (LCT): Life cycle thinking is a very important concept both from the perspective of a circular economy, as well as for the implementation of sustainable and cleaner production and consumption. Life cycle thinking refers to the awareness that products (goods and services) have complex and multi-stage life cycles, which extend beyond the stages directly witnessed by producers and consumers, and have social, economic and environmental consequences. For the above reasons, taking care of the environmental impact generated in all stages of product life cycles and taking extended responsibility are essential elements of consumer characteristics and typology (for more detailed information, please see the questionnaire presented in Table S3 of the Supplementary Materials). In the approach presented, some relevant questions relating to life cycle thinking have been included in the survey designed as part of the methodology.

- Default consumer types: The initial step, preceding the preparation of a questionnaire as an assessment tool, was to establish the default consumer types and the methodology of classification (model answers, model scoring, model final classification). Four "pure" consumer types were distinguished: voluntary simplifiers (VS), beginner voluntary simplifiers (BVS), accidental simplifiers (AS) and non-voluntary simplifiers (NVS). However, in practice, the use of voluntary simplicity principles and life cycle thinking can be limited to just selected areas of daily life and types of decisions. This means that consumers may show a mixed typology. For this reason, mixed consumer types were established (VS/BVS; BVS/AS; AS/NVS), and a classification "per questionnaire part" was made.

- Filtration as a basis for scoring and classification: A core point of the consumer classification was using special filters to reflect the relevance of the answers. The filters were established by members of an expert panel consisting of 10 specialists in environmental science (including eco-design and life cycle management), marketing and psychology. Using these kinds of filters is a pre-existing methodology [48]; however, an entirely new mode of generating the filters (strong, moderate and weak) and scoring the answers was established and used in our approach.

- Universality: The approach is intended to reflect some general consumer characteristics, their mind-set, temperament, thinking perspective and a general way of decision-making. For this reason, it can be universally used, without being limited to one product category. We are aware that products belonging to different product categories are usually purchased in many ways (products purchased rationally with high commitment, products purchased rationally with low commitment, products purchased emotionally with high commitment, products purchased emotionally with low commitment), but this differentiation was beyond the scope of this study, as including this differentiation, the questionnaire would have to be much more complex. In its current form, it includes 70 questions and 350 answer variants, which needed to be modelled to define the default consumer types and all the remaining elements of the methodology.

The procedure for designing a tool for the identification of consumer types, as an overall goal of our project, is presented in Figure 1. It includes four steps from the definition of consumer types (Step 1) to the preparation and verification of the final tool (Step 4).

All steps including consumer type definition (Step 1), questionnaire development (Step 2), assessment of model design (Step 3) and tool preparation and verification (Step 4) are described in detail below. 


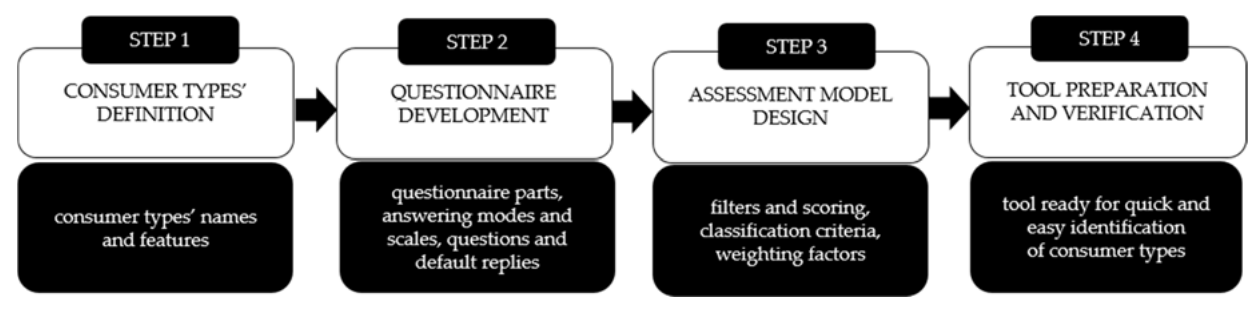

Figure 1. Procedure for designing a tool for the identification of consumer types.

\subsection{Consumer Typology (Step 1)}

What sustainable consumption means for consumers and how to measure it are pivotal questions. In other words: Is it only a matter of behavior during purchasing or is it a whole lifestyle and a thinking perspective implemented by consumers in their daily lives? According to the goal of this paper, an attempt to respond to these questions, as well as an approach to the identification of consumer types by using a practical tool to identify and detect the tendency to practice the principles of sustainable development in daily life were developed. Voluntary simplicity and life cycle thinking were assumed as the pillars of this consumer typology. This unique combination could strengthen the best practice of consumers' behavior and thus facilitate reaching of sustainable consumption goals. Adequate knowledge of the rules for simple living, such as rejecting the high-consumption, materialistic lifestyles of consumer cultures and an affirmation of "the simple life" or "downshifting", is important for offsetting consumption $[67,68]$. Introducing life cycle thinking could justify the application of voluntary simplicity and simple living rules.

To achieve this aim, four types of consumers were distinguished and characterized in terms of many aspects of life: purchasing criteria, lifestyle, mode of decision-making and thinking perspective. The inclusion of life cycle thinking is an essential element of the designed methodology, as well as the environmental relevance of the answers (fully modelled by using the filtration and scoring systems) as the main criterion for consumer classification. Patterned on the general categorization made by different authors in previous research [37,38,48,67-70], the following consumer types were distinguished in our methodology: voluntary simplifiers (VS), beginner voluntary simplifiers (BVS), accidental simplifiers (AS) and non-voluntary simplifiers (NVS). The four mentioned types of consumers represent a "pure" characteristic and clear differences, reflecting different potential, interest and demand for green products and services. Between the VS and their counterpart NVS, two intermediate groups were introduced. One of them is the beginner voluntary simplifiers (BVS). BVS may support some aspects of sustainability (such as buying fair-trade coffee or recycling domestic waste) without either embracing a complete lifestyle change like VS, or completely dismissing ethical or environmental features of products and services they consume, like NVS [67,68]. Accidental simplifiers are people that simplify involuntarily because of economic reasons and are often not concerned with the ethical or environmental aspects of consumption [67-70]. The method of gathering product-related information and the mode of purchase decision-making were adapted from Oates et al. [48]. Default ypes were defined by assuming the characteristics and features of consumers as presented in Table S1 in the Supplementary Information, and the differences between the types have been listed by referring to the following aspects: philosophy of life, de-consumption and dematerialization (simplification), purchasing criteria, lifestyle and environmental choices, mode of purchase decision-making, thinking perspective and life cycle thinking. The consumers classified into these four default types differ significantly in many aspects, but despite this, they can sometimes make similar decisions. This means that although the final purchase decision may be the same, the reasons and motivation can be completely different. For example, VS and AS can decide to buy an energy- and water-efficient washing machine, but while AS did it only because of a price promotion and expected lower energy and water bills, VS made this decision being fully aware of the environmental benefits (in the case of VS, the lower price is not a crucial argument for buying as 
the quality and environmental performance of the product play a central role in VS decision-making). The consumer typology presented in Table S1 has been developed basing on the combination of already existing typologies described in the literature $[37,38,48,67,68]$ with some elements coming from the methodology and practice of environmental life cycle assessment, e.g., cultural perspectives [66], usually used in the life cycle impact assessment phase [65,71]. Some of the pre-existing typologies were established by using cluster analysis, as in the case of studies performed in Turkey $[37,38]$.

\subsection{Questionnaire (Step 2)}

The questionnaire is assumed to be an essential element of the approach presented (Step 2). As the same, but differently-motivated, decisions can be made by consumers belonging to different consumer types, there is a need to prepare the questionnaire respecting the following two issues:

- there are some criteria/behavior/decisions/preferences specific and highly representative of one consumer type, but at the same time, there are others that can be characteristic of more than one consumer type; this observation was the stimulus to design the questionnaire and the assessment model in such a way that the number and kind of consumer types assigned to one single answer play the role of filters;

- some aspects need to have two kinds of questions (A and B), a combination of which gives insight into the consumers' motivations.

The structure of the questionnaire is presented in Table 1 and consists of eight parts: purchasing criteria (PC), mode of decision-making (MDM), sources of general information about products (SGI), sources of environmental information about products (SEI), lifestyle (LS), thinking perspective (TP), life cycle thinking (LCT) and respondent details. Three kinds of scales are used for distinct parts of the questionnaire: an importance scale, an acceptance/conformity scale and a frequency scale. In all cases, a five-point scale is used, as depicted in Table 1. These kinds of scales are frequently used in marketing research to measure frequency (very frequently, frequently, occasionally, rarely, never) and importance (very important, important, moderately important, of little importance, unimportant) [72,73]. They were also used in the previous research on voluntary simplicity, especially the scale where the respondents are asked to respond to the questions by indicating their level of agreement using a five-point Likert scale (applied for example by Roubanis [33]). The most frequently-used scale is the Likert scale from 5 (totally agree) to 1 (totally disagree). It allows one to have a compromise between the conflicting goals of offering enough choice and making things manageable for respondents. In our case study, this sort of scale has been named as the "acceptance/conformity scale" (Table 1). Furthermore, an example of using a frequency of pro-environmental behaviors scale by Iwata [26] can be found.

Table 1. Structure of the questionnaire used in the presented methodology.

\begin{tabular}{|c|c|c|c|c|c|}
\hline & Questionnaire Part & & Mode of Answering & Answer Variants & Number of Items \\
\hline 1 & Purchasing criteria & PC & importance scale & $\begin{array}{l}\text { very important; important; } \\
\text { moderately important; little } \\
\text { importance; not important }\end{array}$ & 90 \\
\hline 2 & Mode of decision-making & MDM & $\begin{array}{l}\text { acceptance/conformity } \\
\text { scale }\end{array}$ & $\begin{array}{l}\text { definitively yes; yes; } \\
\text { moderately yes; rather no; } \\
\text { definitively no }\end{array}$ & 30 \\
\hline 3 & $\begin{array}{c}\text { Sources of general } \\
\text { information about product }\end{array}$ & SGI & frequency scale & \multirow{3}{*}{$\begin{array}{l}\text { always; very often; } \\
\text { moderately often; } \\
\text { sporadically; never }\end{array}$} & 35 \\
\hline 4 & $\begin{array}{l}\text { Sources of environmental } \\
\text { information about product }\end{array}$ & SEI & frequency scale & & 35 \\
\hline 5 & Lifestyle & LS & frequency scale & & 120 \\
\hline 6 & Thinking perspective & $\mathrm{TP}$ & $\begin{array}{l}\text { acceptance/conformity } \\
\text { scale }\end{array}$ & $\begin{array}{l}\text { definitively yes; yes; } \\
\text { moderately yes; rather no; } \\
\text { definitively no }\end{array}$ & 15 \\
\hline 7 & Life cycle thinking & LCT & importance scale & $\begin{array}{l}\text { very important; important; } \\
\text { moderately important; little } \\
\text { importance; not important }\end{array}$ & 25 \\
\hline 8 & Respondents details & & & & \\
\hline
\end{tabular}


In total, the questionnaire includes 70 questions distributed among seven parts (1-7) plus 6 questions in the respondents' details. In Part 5 (lifestyle), two kinds of question are asked (A and B) to make it possible to acquire information not only about decisions and behavior, but also about the consumers' motivations.

\subsection{Filters, Scoring and Final Classification (Step 3)}

As mentioned above, there are certain reasons for looking at the questionnaire questions and answers from the perspective of the designed consumer typology (according to Table S1). The starting point for establishing the assessment model (filters, scoring and classification criteria) was to ascertain what kind of responses can be given by particular consumer types regarding their characteristics presented in Table S1. The answering model and the scoring system were established by a 10-member expert panel including specialists in environmental science, marketing and psychology. The work of the panel resulted in the preparation of an answering model for the entire questionnaire and for 350 possible answers (70 questions $\times 5$ answers). This model reflects the answers assumed to be given by particular consumer types and recognized as the most probable in light of the consumer typology and their characteristics (presented in Table S1). Table 2 presents the answering model for the first part of the questionnaire, purchasing criteria (PC), which includes 18 questions and uses a five-point scale of importance (according to the information presented in Table 1). For each question, the default answers have been modelled according to the consumers' characteristics.

Table 2. Answering model and filters for the first part of the questionnaire (purchasing criteria). AS, accidental simplifiers; NVS, non-voluntary simplifiers; BVS, beginner voluntary simplifiers; VS, voluntary simplifiers.

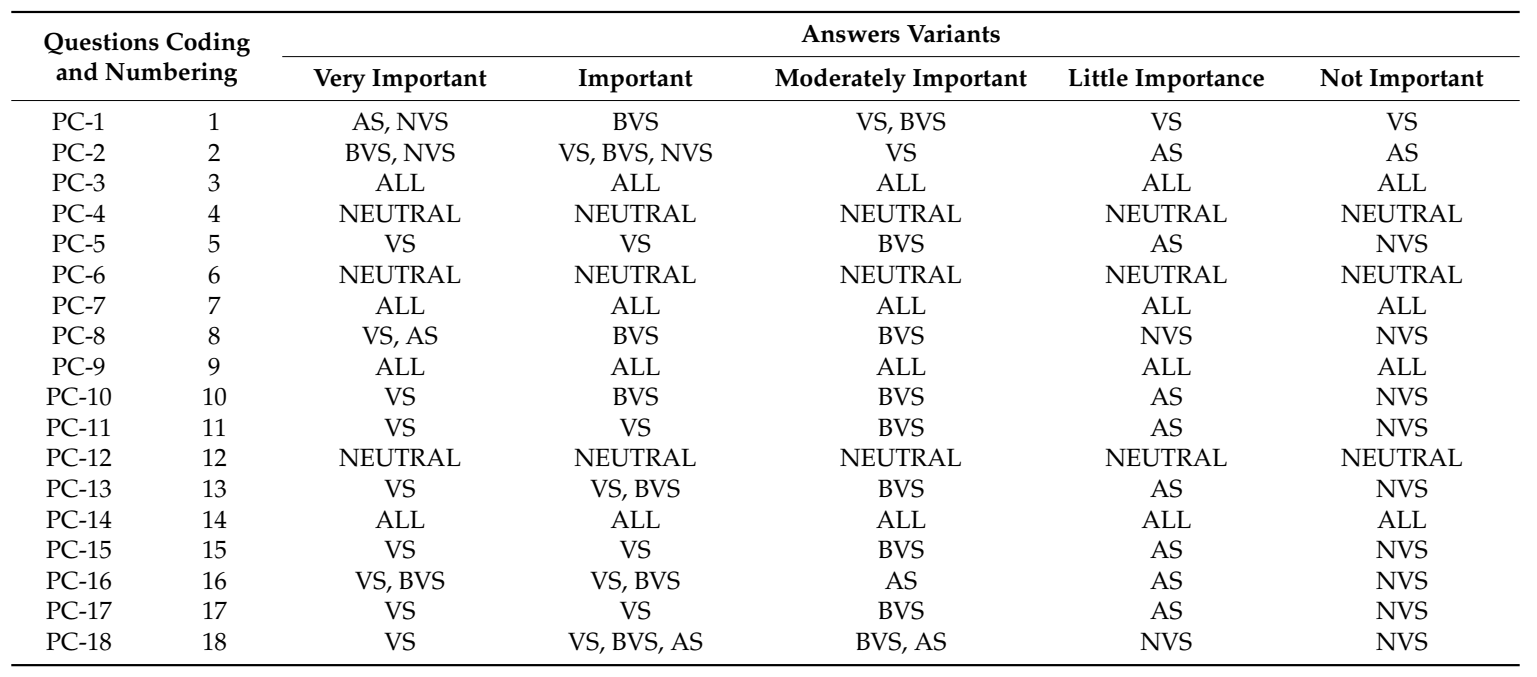

The answering model was the starting point for establishing a system of filters and scoring. It was assumed that if a reply is recognized as answered by only one consumer type, it functions as a strong filter (colored black in Table 2). If a reply is representative of two consumer types, it should be recognized as a moderate filter (medium grey in Table 2). If three consumer types can give the same reply, then it is defined as a weak filter (light grey in Table 2). Additionally, some replies can be given by all consumer types, so they do not have any filtration potential (non-filters colored white in Table 2). However, some differentiations between two kinds of non-filters were made. We distinguished between answers that had no environmental relationship with other replies (called NEUTRAL) and those for which some kind of environmental connections could be identified (called ALL). The filters are randomly distributed among the questionnaire. Table 3 presents the share of particular filters among the parts of the questionnaire. 
Table 3. Share of filters and non-filters in all parts of the questionnaire.

\begin{tabular}{ccccccc}
\hline \multirow{2}{*}{ Questionnaire Part } & \multicolumn{3}{c}{ Filters } & \multicolumn{2}{c}{ Non-Filters } \\
\cline { 3 - 7 } & & Strong & Moderate & Weak & All & Neutral \\
\hline 1 & PC & $50 \%$ & $9 \%$ & $2 \%$ & $22 \%$ & $17 \%$ \\
2 & MDM & $83 \%$ & $17 \%$ & $0 \%$ & $0 \%$ & $0 \%$ \\
3 & SGI & $66 \%$ & $34 \%$ & $0 \%$ & $0 \%$ & $0 \%$ \\
4 & SEI & $83 \%$ & $17 \%$ & $0 \%$ & $0 \%$ & $0 \%$ \\
5 & LS & $60 \%$ & $24 \%$ & $3 \%$ & $6 \%$ & $8 \%$ \\
6 & TP & $100 \%$ & $0 \%$ & $0 \%$ & $0 \%$ & $0 \%$ \\
7 & LCT & $96 \%$ & $4 \%$ & $0 \%$ & $0 \%$ & $0 \%$ \\
\hline
\end{tabular}

The four consumer types distinguished in our approach represent various levels of voluntary simplicity and ecological awareness this means that an answer assumed as a strong filter for VS has a different environmental relevance than another one recognized as a strong filter for AS. Additionally, an answer that is a moderate filter for VS and BVS should be attributed with different environmental relevance than a moderate filter for BVS and AS. This means that some scoring should be designed to reflect the environmental relevance of the filters. The scoring established for filters is presented in Table 4.

Table 4. Scoring for particular filters designed to reflect their environmental relevance.

\begin{tabular}{cccccccc}
\hline \multicolumn{9}{c}{ Filters } & \multicolumn{2}{c}{ Non-Filters } \\
\cline { 1 - 5 } Strong & \multicolumn{9}{c}{ Moderate } & Weak & \\
\hline Consumer Type & Score & Consumer Type & Score & Consumer Type & Score & Consumer Type & Score \\
\hline VS & 4.5 & VS, BVS & 3.8 & VS, BVS, AS & 3.0 & ALL & 0.225 \\
BVS & 3.0 & VS, AS & 3.0 & VS, BVS, NVS & 2.5 & NEUTRAL & 0.0 \\
AS & 1.5 & VS, NVS & 2.3 & VS, AS, NVS & 2.0 & & \\
NVS & 0.0 & BVS, AS & 2.3 & BVS, AS, NVS & 1.5 & & \\
& & BVS, NVS & 1.5 & & & & \\
& & AS, NVS & 0.75 & & & \\
\hline
\end{tabular}

The following assumptions were made to establish the scoring system:

- The highest result possible to achieve, as the sum of scores from all the questions in the entire questionnaire, would mean that (1) a person had replied according to the voluntary simplifier answering model and (2) the scoring fully reflected the maximum scored variant of the VS model;

- The higher the score, the more environmentally friendly the replies given by a respondent;

- There are two factors that make the score higher: environmental relevance (VS $=\max =4.5$, $\mathrm{NVS}=\min =0)$ and the number of possible consumer types that give the answer $(3=\max$, $1=\min$; if 4 , there is no filtering).

- If a reply is assumed to be answered by all four consumer types (non-filter), then two situations are recognized:

Situation 1: The question is environmentally related to other questions. In this case, a score is calculated as $10 \%$ of the mean by Equation (1):

$$
1 / 10 \times((4.5+3+1.5+0)) / 4=0.225(\mathrm{ALL})
$$

ALL = each consumer type (VS, BVS, AS, NVS) is attributed the same score $=0.225$.

Situation 2: The question is not environmentally related to other questions, and it is assumed as NEUTRAL. In this case, a score is assumed as 0 , which means that each consumer type (VS, BVS, AS, NVS) is attributed the same score $=0$. 
As mentioned earlier, it was assumed that it is possible that the same score could be provided by two very different consumer types (e.g., VS and AS). "Energy and water consumption" (PC-8) is a good example as voluntary simplifiers and accidental simplifiers assess it as "very important" (Table 2), but the reasons for this are completely different. VS do it purely for environmental reasons, but AS make their decision just because of cost reduction. To receive the full picture and insight into consumers' motivations, its relationship with other parts of the questionnaire is necessary.

\subsection{Tool Preparation and Verification (Step 4)}

The final consumer classification was established by using intervals calculated as the minimum and maximum values of cumulative scores (sum of scores for all possible answer variants). This means that eight answer models were established as the least (min) and the most (max) environmentally-relevant scenario for each consumer type (VSmin, VSmax, BVSmin, BVSmax ASmin, ASmax NVSmin, NVSmax) and for each questionnaire part. The scores between these scenarios were assumed as mixed types, because in practice, it is possible that the consumers reply differently; e.g., they can answer like VS in relation to one question, but like BVS regarding another one. The classification per one questionnaire part is made as a result of adding the scores for all the questions included in this part. While the questionnaire is filled in by a person, selected replies are compared with the default scores included in the answering models and incorporated into the calculating tool (an example of the scoring configuration for Part 1 of the questionnaire presented in Figure 2). The results are added and then compared with the intervals, and the classification per part is disclosed to the tool administrator. The screens with the answering page and the classification intervals for the first part of the questionnaire (purchasing criteria) are presented in Figure S1 (Supplementary Information) and Figure 3, respectively. An example of the scoring configuration (B) for Part 5, life style, is shown in Figure S2. In Section 3, a detailed verification of the designed tool, as well as the specific results of a pilot survey are presented.

\section{Scoring configuration}

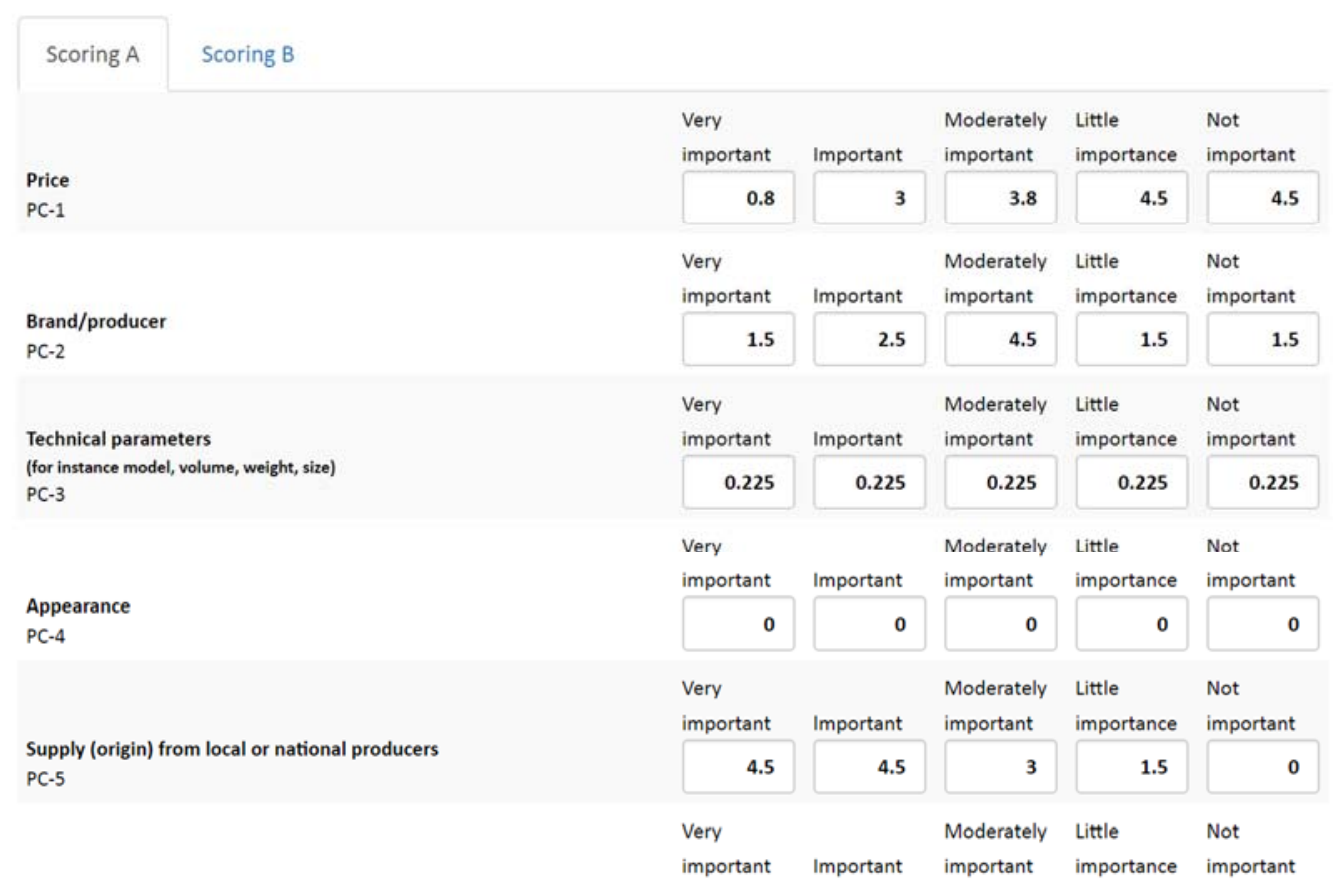

Figure 2. Example of the scoring configuration (A) for Part 1 of the questionnaire (purchasing criteria). 


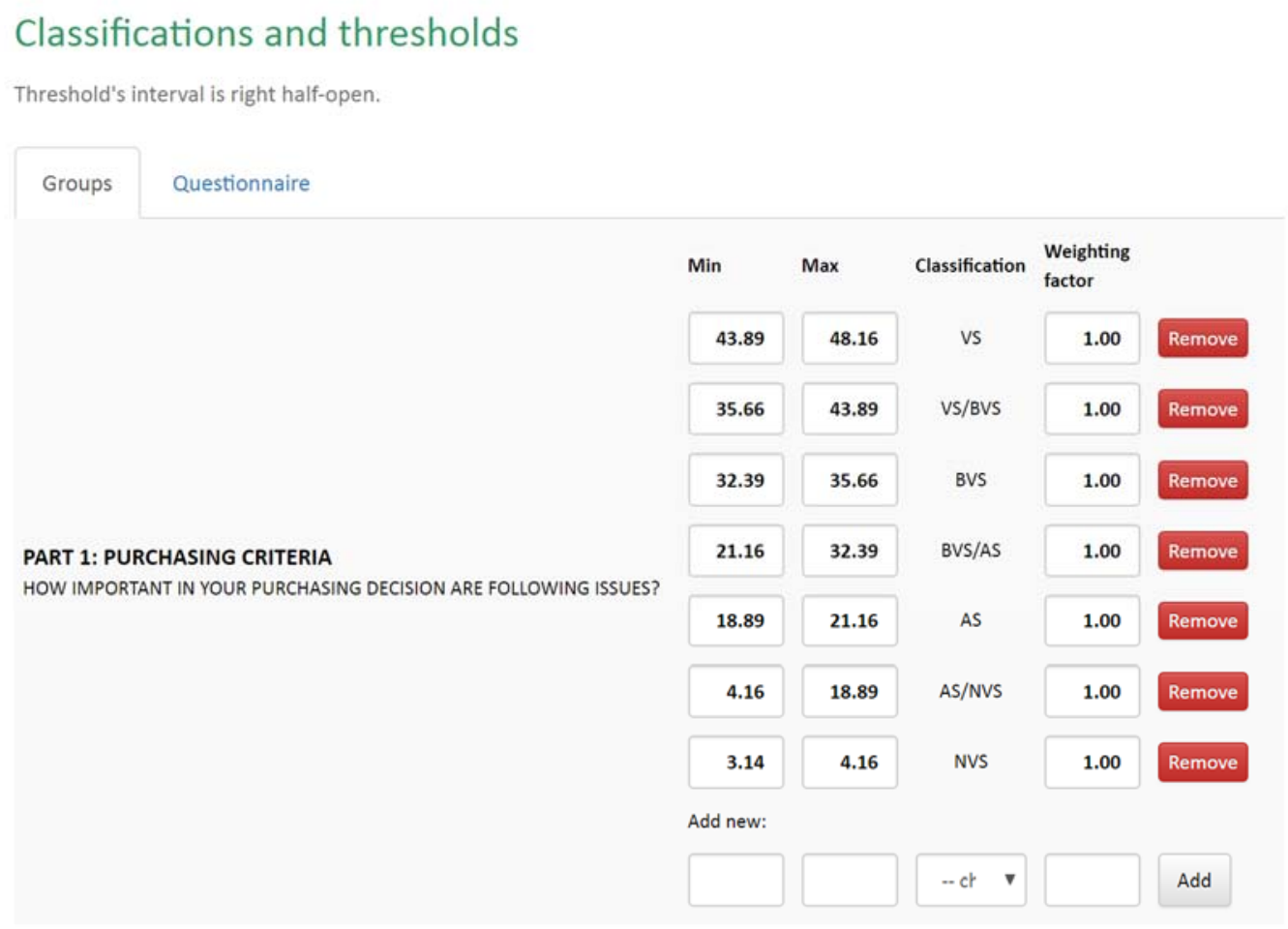

Figure 3. Classification intervals for Part 1 of the questionnaire (purchasing criteria).

\section{Results}

In order to verify the designed tool, a pilot survey was performed between June and December, 2017. The survey sample numbered 180 respondents and was selected from various regions of Poland. A general description of the sample is presented in Table 5. Seventy percent of the surveyed people were women, while the remaining 30\% were men. In both cases, mostly people with a medium or high educational attainment level participated. The respondents were asked to describe their financial situation, and they most often gave the reply "average" (46\% of women, $34 \%$ of men) or "good" (44\% of women, $41 \%$ of men).

Table 5. Description of the sample evaluated in the pilot survey in terms of gender, age, education and financial situation $(n=180)$.

\begin{tabular}{cccccccccccc}
\hline & \multicolumn{3}{c}{ Women $(\boldsymbol{n = 1 2 7})$} & \multicolumn{6}{c}{ Men $(\boldsymbol{n}=\mathbf{5 3})$} \\
\hline \multicolumn{2}{c}{ Age (Years) } & $\begin{array}{c}\text { Educational } \\
\text { Attainment level }\end{array}$ & $\begin{array}{c}\text { Declared Financial } \\
\text { Situation }\end{array}$ & Age (Years) & \multicolumn{2}{c}{$\begin{array}{c}\text { Educational } \\
\text { Attainment Level }\end{array}$} & $\begin{array}{c}\text { Declared Financial } \\
\text { Situation }\end{array}$ \\
\hline $15-24$ & 74 & High & 37 & Very good & 8 & $15-24$ & 24 & High & 23 & Very good & 10 \\
\hline $25-34$ & 13 & $\begin{array}{c}\text { Incomplete } \\
\text { higher }\end{array}$ & 30 & Good & 56 & $25-34$ & 6 & $\begin{array}{c}\text { Incomplete } \\
\text { higher }\end{array}$ & 5 & Good & 22 \\
\hline $35-54$ & 24 & Medium & 58 & Average & 59 & $35-54$ & 13 & Medium & 23 & Average & 18 \\
\hline $55-64$ & 10 & Low & 2 & Bad & 4 & $55-64$ & 6 & Low & 2 & Bad & 3 \\
\hline$\uparrow 65$ & 6 & & & & & $\uparrow 65$ & 4 & & & & \\
\hline
\end{tabular}

The consumer classification obtained in the pilot survey (Figure 4) shows lower environmental awareness among the surveyed respondents in relation to the following parts of the questionnaire: purchasing criteria, mode of decision-making, sources of general information about products and sources of environmental information about products. BVS/AS and BVS were the dominant consumer types within purchasing criteria (104 persons) and mode of decision-making (114 persons); however, 
a proportion of VS/BVS was also visible (57 persons for Part 1 and 55 for Part 2). In the case of Part 4 (source of environmental information about products), a major contribution was made by consumer types with lower environmental awareness: BVS/AS (56\%), AS (10\%) and AS/NVS (18\%). The last three questionnaire parts (Parts 5, 6 and 7) showed visibly better results in terms of the environmental awareness of respondents, as types VS/BVS and VS contributed mostly.

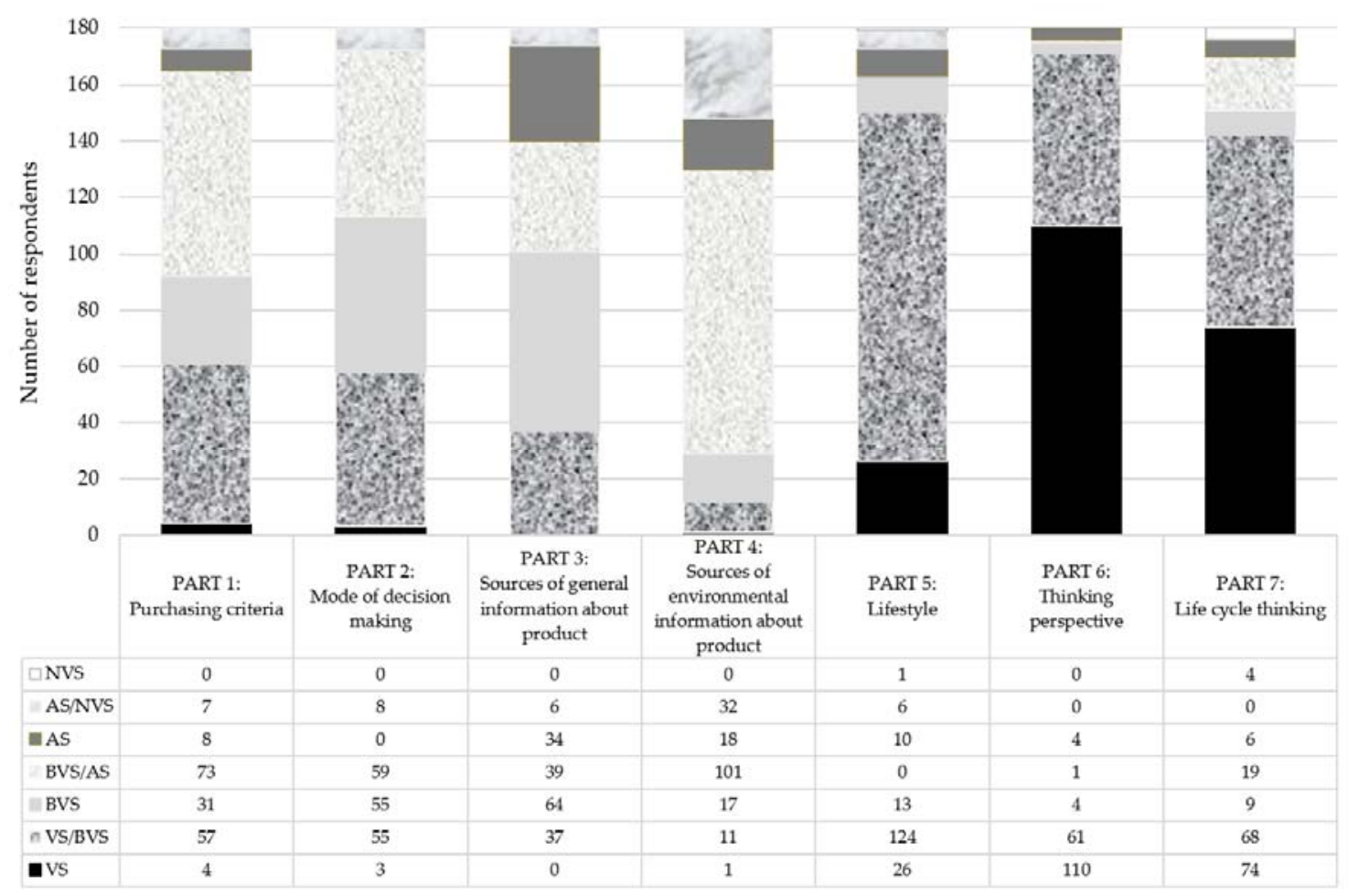

Figure 4. The respondent classification (per part of the questionnaire) obtained in the pilot survey by using the proposed methodology and tool.

The results mean that in the case of Questionnaire Parts 1, 2, 3 and 4, the surveyed respondents did not select replies that were a strong filter for the highest environmentally-responsible consumer type (=low share of VS). It also means that the respondents made either "neutral" choices or choices with a lower environmental relevance (strong filters for BVS/AS, AS, AS/NVS, NVS). On the other hand, the same respondents were better in terms of long-term thinking, a sense of intergenerational equity and taking into account the different life cycle stages of products (=higher share of VS and BVS in Parts 5, 6 and 7).

The final scores and final classifications for each questionnaire part obtained in the pilot survey are presented in Table 6. The environmental awareness of the respondents surveyed differed between the questionnaire parts. Whereas good results were obtained for lifestyle, thinking perspective and life cycle thinking, the scores for purchasing criteria, mode of decision-making and sources of information were noticeably worse. This means that a potential strategy for improving the sustainable consumption patterns formulated in the case of the members of the pilot sample should be focused on finding the ways to improve their decision-making in the areas described by the first four questionnaire parts. Their environmental awareness relating to lifestyle, thinking perspective and life cycle thinking can be assumed to be very good or satisfactory. It is worth emphasizing that the significant contribution of VS and VS/BVS in the results for Questionnaire Parts 5,6 and 7 may be an effect of the fact that, to some extent, the pilot sample included students familiar with eco-designs. If it were not, then the results for these parts would probably be worse. On the other hand, the very small share of respondents with a low level of education and very poor material situation resulted in a negligible share of NVS (Figure 4). 
Table 6. Final scores and respondent classifications obtained in the pilot survey (per part of the questionnaire, $n=180$ ).

\begin{tabular}{lccc}
\hline & Questionnaire Part & Final Score (Mean) & Classification \\
\hline 1 & Purchasing Criteria & 31.9 & BVS/AS \\
2 & Mode of Decision-Making & 16.3 & BVS \\
3 & Sources of General Information about Products & 17.7 & BVS \\
4 & Sources of Environmental Information about Products & 14.4 & BVS/AS \\
5 & Lifestyle & 66.8 & VS/BVS \\
6 & Thinking Perspective & 12.5 & VS/BVS \\
7 & Life Cycle Thinking & 18.6 & VS/BVS \\
\hline
\end{tabular}

The results obtained for each questionnaire part can be analyzed further. Figure 5 presents the replies given by the respondents in relation to the questions included in Part 1 . The importance scale was used, and it was possible to select one of the following answers: very important, important, moderately important, little importance, not important. As the presented results show, in the opinion of the respondents, the most important issues regarding "purchasing criteria" are price, consumption of energy and water, technical parameters, product durability, appearance, product availability, delivery time and warranty conditions.

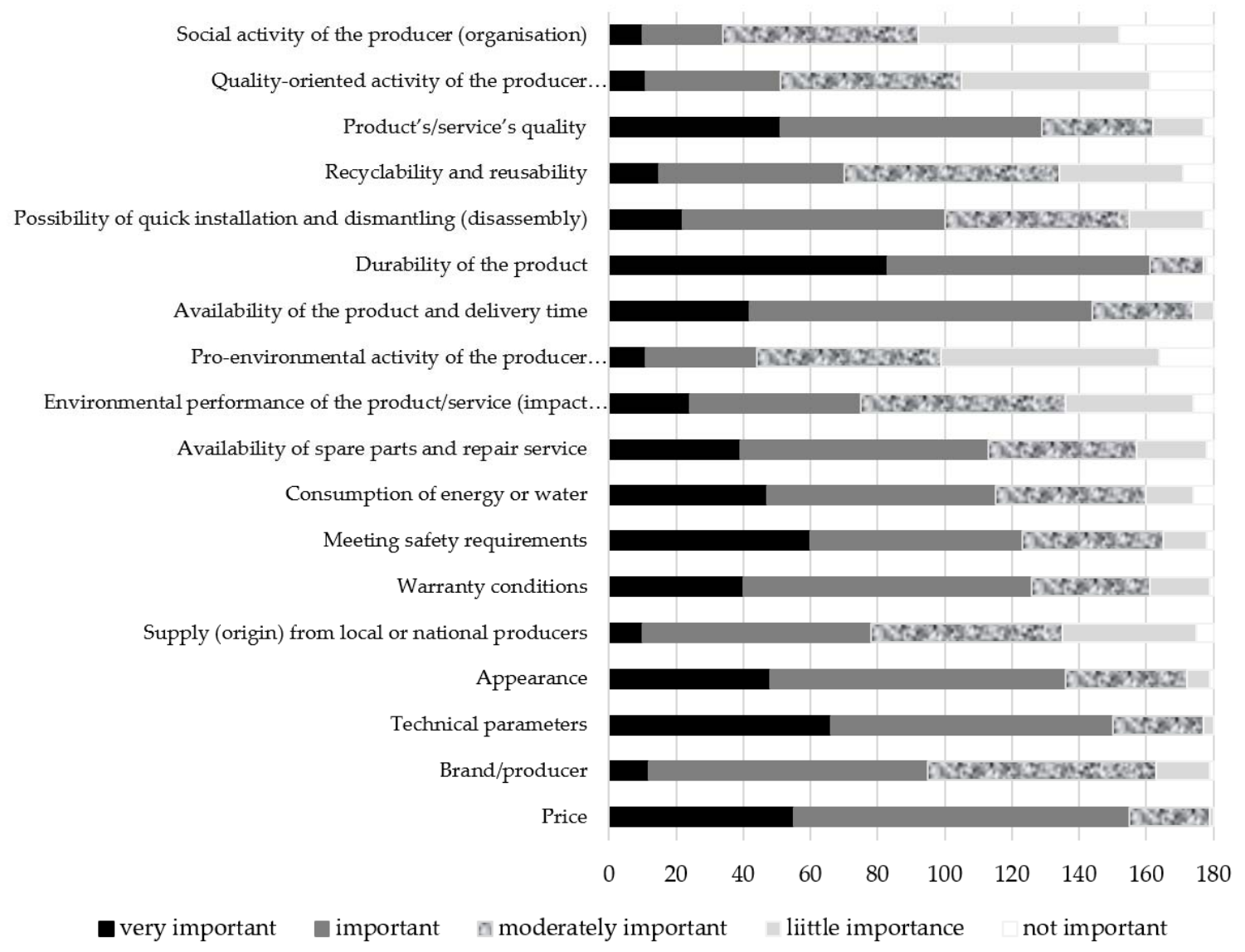

Figure 5. Answers given by respondents to the questions included in Part 1 of the questionnaire (purchasing criteria, $n=180$ ).

It is worth emphasizing that in our methodology, the final scores (Table 6) did not reflect the importance of the questions, but the environmental relevance of the replies given to those questions. The stronger the environmental relevance of a reply (assessed by the filtration system), the higher 
the score obtained. This comment is important from the perspective of the results presented in Figure 5, as in case of one question, the replies "very important/always/definitely yes" could be attributed as having the highest environmental relevance; while in the case of another, opposite replies like "not important/never/definitely no" could be recognized as the most environmentally preferable. In the questionnaire as a whole, there are some issues recognized as neutral; for example "appearance", "guaranty conditions" and "availability of the product and delivery time" (in Part 1). It was assumed that they did not have the potential to differentiate the respondents surveyed in terms of their environmental awareness. All these neutral elements had their score designated as "zero" (Table 4), regardless of the reply given by respondents. This means that even if a respondent gives the reply "very important" to "appearance" (which can be observed in Figure 5), this reply is not included in the final score and does not impact its value. This way, the final score was "cleared" of neutral elements and can be seen as a pure measure as to the environmental relevance of the choices made by consumers. It was decided to place such neutral elements in the questionnaire because they can be valuable for interpretation and for gaining comprehensive knowledge about consumer preferences and behavior. The composition of the questionnaire, in terms of the numbers and kinds of filters, is presented in Table S1-2. It shows that 24 non-filters were included, being located in two parts of the questionnaire: Part 1, purchasing criteria ( 35 non-filters, including 15 neutral), and Part 5, lifestyle (16 non-filters, including nine neutral). The whole questionnaire includes 350 filters with the majority being strong ones (strong filters $=233$, moderate filters $=61$, weak filters $=5$, non-filters $=51$ ). Part 1 and Part 5 include the highest number of questions and the highest number of strong filters for VS, so the environmental relevance of both of these parts is very high (393 out of 749 points).

\section{Discussion}

The following aspects should be recognized as the strong points of the approach used: the comprehensiveness of the questionnaire (various aspects of life included), the ability to reflect the variability of answers by using filters, the quantitative character of the results, the fast and easy procedure, the universality and the inclusion of life cycle aspects. The arbitrariness of filtration and scoring is a potential weakness of the model, and for these reasons, an expert panel was formed. However, the proposed tool was designed to ensure flexibility, and it is fully possible to make improvements and changes in the values of the scores and/or intervals. In our model, the main criterion for making a distinction between consumer types is their tendency to practice the principles of voluntary simplicity and life cycle thinking. As was shown in the examples of previous research mentioned above, sustainability can be a lifestyle. Therefore, as was found in both the previous and our own research, a sustainable lifestyle is fully and consciously possible to implement in daily life (voluntary simplifiers) or can be a fashion with occasionally- and consciously-made sustainability-oriented decisions (beginner voluntary simplifiers). It can also occur as an accidental and unconscious element in life (accidental simplifiers) or, finally, it can be a completely unknown and disregarded concept (non-voluntary simplifiers). Voluntary simplifiers are ready to reduce consumption and pay a higher price for the cause of higher quality and pro-environmental features and are therefore less susceptible to greenwashing, as they use verified product-related information taken from professional and primary sources.

The results obtained in the pilot survey show that the tendency of the people surveyed to follow voluntary simplicity principles differs and depends on the area of life. The recruitment strategy, based heavily on young people (students familiar with eco-design), accounts for the relatively high number of VS and VS/BVS in the classification results for lifestyle, thinking perspective and life cycle thinking. Compared to other studies in this area, the results differ according to age, level of education and material status. As a whole, VS are identified as middle-aged people, well educated (more highly educated than the general population) and financially secure (household income over the national average), inter alia $[23,27,33,35]$. 
Compared to similar research investigating the same population group (young people), our results differ. The findings of the studies of Roubanis [33], Isaka [27] and Fogarty's [74] support the hypothesis that a high level of VSL is very rare in college-age students. In an investigation comparing environmentally-responsible consumerism (ERC) and the voluntary simplicity lifestyle (VSL), between Meredith College students in the USA [33] and Japanese female college students in Osaka Shoin Women's University (Osaka, Japan) [32], it was shown that both groups of respondents were striving to meet their needs of self-esteem and efficacy through their consumption behaviors. Despite young respondents who practice VSL declaring their intention of taking action towards putting their beliefs into consumer behavior practice, the majority of them are non-self-actualizing. Although VSL influences become more mainstream in social and physical settings, for young people, the influence of the global consumer culture is very high, so their consumption is affected by superficiality and reckless choices. On the other hand, conscious and unconscious factors from the consumers' social and environmental settings are widely recognized as powerful determinants of consumption behavior $[27,74-76]$. This hypothesis supports the results from our investigation. Our participants consisted mainly of students familiar with eco-design and the conception of life cycle thinking. Because of the negligible share in the pilot sample of people with a low level of education and poor material situation, only single cases of NVS were recorded.

A potential for improving sustainable consumption patterns lies both in BVS and AS, although in both cases, it has a different nature. Based on the scoring, it can be stated that BVS's decisions are not driven by saving money, but by fashion and a free choice. Both VS and BVS can afford to buy expensive, high quality and durable products, but the difference between them is that the VS do it "by nature", while BVS only do it sporadically. AS also tend to practice sustainability, but in their case, it is limited to selected areas of life and is made unconsciously and mainly for cost-saving reasons. Their decisions are not driven by ideology, fashion or free choice, but mostly by economic reasons. They also reduce their consumption, give products a second life and new functionality and save energy and water mainly for cost-saving reasons. In the case of AS, a challenge would be to make them aware of their sustainability choices and to show them the value of de-consumption. There is a risk that if AS had more money, they would start increasing their consumption and abandon their unintentional sustainability. However, by making AS aware of the value hidden in their unconscious sustainability, this risk can be reduced. The four mentioned consumer types represent clear and "pure" characteristics. However, in practice, the use of voluntary simplicity principles and life cycle thinking can be limited to selected areas of daily life only. For this reason, the questionnaire and assessment tool were designed to consist of seven parts, which reflect various aspects of life and, moreover, enable the mixed consumer types to be established.

\section{Conclusions}

In this paper, an approach for the identification of consumer types by using a practical tool was proposed, able to identify and detect the tendency of consumers to practice the principles of sustainable development in daily life. Voluntary simplicity and life cycle thinking were assumed to be the pillars of this consumer typology. Four types of consumer were distinguished and characterized in terms of many aspects of life: purchasing criteria (PC), mode of decision-making (MDM), sources of general information about products (SGI), sources of environmental information about products (SEI), lifestyle (LS), thinking perspective (TP) and life cycle thinking (LCT). The inclusion of life cycle thinking is an essential element of the designed methodology, as well as the environmental relevance of the answers (fully modelled by using the filtration and scoring systems) as the main criterion for consumer classification. The methodology was successfully verified by a pilot survey performed among 180 respondents. The results were impacted by the composition of the pilot sample, with a noticeable share of young people familiar with eco-design (which resulted in a major contribution from VS and VS/BVS in Questionnaire Parts 5, 6 and 7). On the other hand, the small participation of respondents with a low level of education and poor financial situation resulted in a negligible contribution from 
NVS types. A more comprehensive survey including a broader spectrum of respondents (in terms of nationality, gender, age, education, financial situation and employment) is planned to be carried out in the near future as part of a larger scientific project.

Supplementary Materials: The following are available online at http:/ /www.mdpi.com/2071-1050/10/6/1826/ s1, Figure S1: Characteristics of the four distinguished consumer types in seven areas, Table S2: Composition of the questionnaire-a number of filters and their environmental relevance, Table 3: The questionnaire's content-questions displayed to respondents, Figure S1: Part of answering page of the questionnaire (Part 1-Purchasing Criteria), Figure S2: Example of scoring configuration (B) for Part 5 of the questionnaire (Lifestyle).

Author Contributions: C.D. was in charge of the discussion of the methodology and the results, verification of the final version of the tool and checking the English. P.G. was in charge of the discussion of the methodology and the results, the literature review, verification of the final version of the tool and proof reading of the final submission. P.K. was in charge of the discussion of the methodology, coordinating the preparation of the tool and supporting the pilot survey. K.P.-L. was responsible for discussing the methodology, supporting the pilot survey and verifying the final version of the tool. A.L. was responsible for designing the methodology and a prototype of the tool, writing the manuscript and coordinating the research. J.W. was in charge of organizing the expert panel, coordinating the pilot survey and making the final check of the manuscript.

Conflicts of Interest: The authors declare no conflicts of interest.

\section{References}

1. Brundtland, G.H. Our Common Future. Report of the World Commission on Environment and Development. 1987. Available online: http:/ / www.un-documents.net/our-common-future.pdf (accessed on 30 May 2018).

2. Ascher, W. Long-term strategy for sustainable development: Strategies to promote far-sighted action. Sustain. Sci. 2006, 1, 15-22. [CrossRef]

3. Eurostat. Sustainable Development in the European Union; 2015 Monitoring Report of the EU Sustainable Development Strategy; Publications Office of the European Union: Luxembourg, 2015; ISBN 978-92-79-49391-1.

4. European Commission. Proposal for a New European Consensus on Development Our World, Our Dignity, Our Future. COM (2016) 740 Final, Strasbourg. 22 November 2016. Available online: https:/ / ec.europa.eu/europeaid/sites/devco/files/communication-proposal-new-consensusdevelopment-20161122_en.pdf (accessed on 30 May 2018).

5. Cheung, N.F.; Rapacioli, S.; Witt, K. SMEs Set Their Sights on Sustainability-Case Studies of Small and Medium-Sized Enterprises (SMEs) from the UK, US and Canada; The Canadian Institute of Chartered Accountants: Toronto, ON, Canada; The American Institute of CPAs: Durham, NC, USA; Chartered Institute of Management Accountants: London, UK, 2011; ISBN 978-1-55385-616-0.

6. Traverso, M.; Asdrubali, F.; Francia, A.; Finkbeiner, M. Towards life cycle sustainability assessment: An implementation to photovoltaic modules. Int. J. Life Cycle Assess. 2012, 17, 1068-1079. [CrossRef]

7. Meqdadi, O.; Johnsen, T.; Johnsen, R. The Role of SME Suppliers in Implementing Sustainability. In Proceedings of the IPSERA Conference, Naples, Italy, 1-4 April 2012; Available online: https: / halshs.archives-ouvertes.fr / file/index/docid/824677/filename/The_Role_of_SME_Suppliers_ in_Implementing_Sustainability.pdf (accessed on 30 May 2018).

8. Oekom Research AG. Corporate Responsibility Review 2017: Global Transformation Processes-Are Companies Already on the Right Track? Oekom Research AG: Munich, Germany, 2017.

9. Den Boer, J.; den Boer, E.; Jager, J. LCA-IWM: A decision support tool for sustainability assessment of waste management systems. Waste Manag. 2007, 27, 1032-1045. [CrossRef] [PubMed]

10. Orecchini, F.; Valitutti, V.; Vitali, G. Industry and academia for a transition towards sustainability: Advancing sustainability science through university-business collaborations. Sustain. Sci. 2012, 7 (Suppl. 1), 57-73. [CrossRef]

11. Lozano, F.J.; Lozano, R. Developing the curriculum for a new Bachelor's degree in Engineering for Sustainable Development. J. Clean. Prod. 2014, 64, 136-146. [CrossRef]

12. Lozano, R.; Ceulemans, K.; Alonso-Almeida, M.; Huisingh, D.; Lozano, F.J.; Waas, T.; Lambrechts, W.; Lukman, R.; Hugé, J. A review of commitment and implementation of sustainable development in higher education: Results from a worldwide survey. J. Clean. Prod. 2015, 108, 1-18. [CrossRef] 
13. World Commission on Environment and Development. Our Common Future; Oxford Paperbacks; Oxford University Press: New York, NY, USA, 1987.

14. United Nations, Department of Economics and Social Affairs (DESA). The Sustainable Development Goals Report 2017; United Nations Statistics Division Statistical Services Branch: New York, NY, USA, 2017; ISBN 2518-3958.

15. Van den Bergh, J.C.J.M. Relax about GDP growth: Implications for climate and crisis policies. J. Clean. Prod. 2010, 18, 540-543. [CrossRef]

16. Alcott, B. The sufficiency strategy: Would rich-world frugality lower environmental impact? Ecol. Econ. 2008, 64, 770-786. [CrossRef]

17. Janikowski, R. Imperative for Sustainable Everyday (orig. Nachhaltigkeit Als Imperativ des Alltags). Hum. Soc. Sci. 2014, 21, 71-82. [CrossRef]

18. Martinho, G.; Pires, A.; Portela, G.; Fonseca, M. Factors affecting consumers' choices concerning sustainable packaging during product purchase and recycling. Resour. Conserv. Recycl. 2015, 676, 58-68. [CrossRef]

19. McGregor, S.L.T. Understanding consumer moral consciousness. Int. J. Consum. Stud. 2006, 30, 164-178. [CrossRef]

20. Durning, A. Limiting consumption: Toward a sustainable culture. Futurist 1991, 5, 10-15.

21. Ebero, A.; Hershey, J.; Vining, J. Reducing solid waste: Linking recycling to environmentally responsible consumerism. Environ. Behav. 1999, 31, 107-135. [CrossRef]

22. Boujbel, L.; d'Astous, A. Voluntary simplicity and life sat-isfaction: Exploring the mediating role of consumption desires. J. Consum. Behav. 2012, 11, 487-494. [CrossRef]

23. Huneke, M.E. The face of the un-consumer: An empirical examination of the practice of voluntary simplicity in the United States. Psychol. Mark. 2005, 22, 527-550. [CrossRef]

24. Jackson, T. Live better by consuming less? Is there a "double dividend" in sustainable consumption? J. Ind. Ecol. 2005, 9, 19-36. [CrossRef]

25. Jackson, T. Prosperity without Growth: Economics for a Finite Planet; Earthscan: London, UK, 2009; ISBN 978-1-84407-894-3.

26. Iwata, O. Perceptual and behavioural correlates of voluntary simplicity lifestyles. Soc. Behav. Personal. Int. J. 1999, 27, 379-386. [CrossRef]

27. Fraj, E.; Martinez, E. Ecological consumer behaviour: An empirical analysis. Int. J. Consum. Stud. 2007, 31, 26-33. [CrossRef]

28. Brown, K.W.; Kasser, T. Are psychological and ecological well-being compatible? The role of values, mindfulness, and lifestyle. Soc. Indic. Res. 2006, 74, 349-368. [CrossRef]

29. Burgiel, A.; Sowa, I.; Zrałek, J. Voluntary simplicity-sustainable alternative to overconsumption. Sci. J. Wars. Univ. Life Sci. Eur. Policies Financ. Mark. 2015, 13, 18-29, ISSN 2081-3430.

30. Alexander, S. The Voluntary Simplicity Movement: Reimagining the Good Life beyond Consumer Culture. Int. J. Environ. Cult. Econ. Soc. Sustain. 2011, 7, 133-150, ISSN 1832-2077.

31. Elgin, D.; Mitchell, A. Voluntary Simplicity. Co-Evolution Quarterly. 1977; pp. 1-40. Available online: http: / / www.duaneelgin.com/wp-content/uploads/2010/11/voluntary_simplicity.pdf (accessed on 30 May 2018).

32. Iwata, $\mathrm{O}$. An evaluation of consumerism and lifestyle as correlates of a voluntary simplicity lifestyle. Soc. Behav. Personal. 2006, 34, 557-568. [CrossRef]

33. Roubanis, J.L. Comparison of Environmentally Responsible Consumerism and Voluntary Simplicity Lifestyle between U.S. and Japanese Female College Students. Fam. Consum. Sci. Res. J. 2008, 37, 210-218. [CrossRef]

34. Kala, L.; Galčanová, L.; Pelikán, V. Narratives and Practices of Voluntary Simplicity in the Czech Post-Socialist Context. Sociol. Časopis Czech Sociol. Rev. 2017, 53, 833-855. [CrossRef]

35. Zavestoski, S. The social-psychological bases of anticonsumption attitudes. Psychol. Mark. 2002, 19, 149-165. [CrossRef]

36. Shaw, D.; Newholm, T. Voluntary simplicity and the ethics of consumption. Psychol. Mark. 2002, 19, 167-185. [CrossRef]

37. Erdoğmuş, I.; Karapınar, E. Understanding Levels of Voluntary Simplicity in Turkey. Boğaziçi J. Rev. Soc. Econ. Adm. Stud. 2015, 29, 1-19. [CrossRef]

38. Sertoğlu, A.E.; Bozoklu, C.P.; Korkmaz, S. Voluntary Simplicity, Values and Lifestyles: A Case of Ankara-Turkey. J. Theory Pract. Mark. 2016, 2, 21-50. 
39. Lewandowska, A.; Borusiak, B.; Dierks, G.P.; Jerzyk, E.; Kurczewski, P.; Sobierajewicz, J.; Suh, S.; Witczak, J. Neuro-marketing Tools for Assessing the Communication Effectiveness of Life Cycle Based Environmental Labelling-Procedure and Methodology. In Designing Sustainable Technologies, Products and Policies. From Science to Innovation; Benetto, E., Gericke, K., Guiton, M., Eds.; Springer: New York, NY, USA, 2018; ISBN 978-3-319-66980-9, under publication.

40. Young, W.; Hwang, K.; McDonald, S.; Oates, C. Understanding individual decision-making for sustainable consumption. International Workshop on Driving Forces of and Barriers to Sustainable Consumption. LIFE, School of the Environment, University of Leeds. 2004. Available online: https:/ /s3-eu-west-1.amazonaws.com/esrcfiles/outputs/trwpwIS7r0qG3FHDi_I2jA/CMyApZb2oUe5rgbpx6LvVQ.pdf (accessed on 30 May 2018).

41. Ottman, J. The New Rules of Green Marketing: Strategies, Tools, and Inspiration for Sustainable Branding; Greenleaf Publishing Limited: Sheffield, UK, 2010; ISBN 978-1906093-44-0.

42. McDonald, S.; Oates, C.J.; Alevizou, P.J.; Young, C.W.; Hwang, K. Individual strategies for sustainable consumption. J. Mark. Manag. 2012, 28, 445-468. [CrossRef]

43. Sharma, M.; Rani, L. Environmentally Sustainable Consumption: A Review and Agenda for Future Research. Glob. J. Financ. Manag. 2014, 6, 367-374, ISSN 0975-6477.

44. Terlau, W.; Hirsh, D. Sustainable Consumption and the Attitude-Behaviour-Gap Phenomenon-Causes and Measurements towards a Sustainable Development. In Proceedings of the 9th International European Forum on System Dynamics and Innovation in Food Network, Innsbruck, Austria, 9-13 February 2015; Deiters, J., Rickert, U., Schiefer, G., Eds.; pp. 119-214, ISSN 2194-511X. Available online: https:/ /ageconsearch.umn. edu/record/206233/files/16-Terlau\%20Hirsch.pdf (accessed on 30 May 2018).

45. Elgin, D.; Mitchell, A. Voluntary simplicity. Plan. Rev. 1977, 5, 13-15. [CrossRef]

46. Victor, P. Managing without Growth: "Slower by Design, Not Disaster"; Edward Elgar Publishing Limited: Cheltenham, UK, 2008; ISBN 9781847200785.

47. Alexander, S.; Ussher, S. The Voluntary Simplicity Movement: A Multi-National Survey Analysis in Theoretical Context Simplicity Institute Report 11a. 2011. Available online: http://simplicityinstitute. org/wp-content/uploads / 2011/04/The-Voluntary-Simplicity-Movement.pdf (accessed on 30 May 2018).

48. Oates, C.; McDonald, S.; Alevizou, P.; Hwang, K.; Young, W.; McMorland, L.-A. Marketing sustainability: Use of information sources and degrees of voluntary simplicity. J. Mark. Commun. 2008, 14, 351-365, ISSN 1895-6912. [CrossRef]

49. Kronenberg, J.; lida, N. Simple Living and Sustainable Consumption. Probl. Sustain. Dev. 2011, 6, 67-74, ISSN 2083-8611.

50. Zrałek, I. Voluntary Simplicity—Sustainable Lifestyle of Contemporary Consumers. Stud. Ekon. Zesz. Nauk. Uniw. Ekon. Katowicach 2015, 231, 139-158.

51. Lee, M.S.W.; Ahn, C.S.Y. Anti-consumption, materialism, and consumer wellbeing. J. Consum. Aff. 2016, 50, 18-47. [CrossRef]

52. Ballantine, P.W.; Creery, S. The consumption and disposition behaviour of voluntary simplifiers. J. Consum. Behav. 2010, 9, 45-56. [CrossRef]

53. Iyer, R.; Muncy, J.A. Purpose and object of anti-consumption. J. Bus. Res. 2009, 62, 160-168. [CrossRef]

54. Lietaert, M. Cohousing's relevance to degrowth theories. J. Clean. Prod. 2010, 18, 576-580. [CrossRef]

55. Laiola, E.; Giungato, P. Wind characterization in Taranto city as a basis for innovative sustainable urban development. J. Clean. Prod. 2018, 172, 3535-3545. [CrossRef]

56. Cattaneo, C.; Gavalda, M. The experience of rurban squats in Collserola, Barcelona: What kind of degrowth? J. Clean. Prod. 2010, 18, 581-589. [CrossRef]

57. Matthey, A. Less is more: The influence of aspirations and priming on well-being. J. Clean. Prod. 2010, 18, 567-570. [CrossRef]

58. Lindstrom, M.; Kotler, P. Brand Sense: Build Powerful Brands through Touch, Taste, Smell, Sight and Sound; Free Press: New York, NY, USA, 2005; ISBN 0743267842.

59. Hamilton, C. Consumerism, self-creation and prospects for a new ecological consciousness. J. Clean. Prod. 2010, 18, 571-575. [CrossRef]

60. Van Griethuysen, P. Why are we growth-addicted? The hard way towards edgrowth in the involutionary western development path. J. Clean. Prod. 2010, 18, 590-595. [CrossRef]

61. Peyer, M.; Balderjahn, I.; Seegebarth, B.; Klemm, A. The role of sustainability in profiling voluntary simplifiers. J. Bus. Res. 2017, 70, 37-43. [CrossRef] 
62. Hueting, R. Why environmental sustainability can most probably not be attained with growing production. J. Clean. Prod. 2010, 18, 525-530. [CrossRef]

63. Spangenberg, J.H. The growth discourse, growth policy and sustainable development: Two thought experiments. J. Clean. Prod. 2010, 18, 561-566. [CrossRef]

64. European Commission. Making Sustainable Consumption and Production a Reality-A Guide for Business and Policy Makers to Life Cycle Thinking and Assessment; Publications Office of the European Union: Luxembourg, 2010; p. 32, ISBN 978-92-79-14357-1.

65. Hofstetter, P. Perspectives in Life Cycle Impact Assessment-A Structured Approach to Combine Models of the Technosphere, Ecosphere and Valuesphere; Springer: New York, NY, USA, 1998; ISBN 978-1-4615-5127-0.

66. Thompson, M.; Ellis, R.; Wildavsky, A. Cultural Theory; Avalon Publishing: Emeryville, CA, USA, 1990.

67. McDonald, S.; Oates, C.J.; Young, C.W.; Hwang, K. Toward Sustainable Consumption: Researching Voluntary Simplifiers. Psychol. Mark. 2006, 23, 515-534. [CrossRef]

68. Craig-Lees, M.; Hill, C. Voluntary Simplifiers and Non-Voluntary Simplifiers: Exploring Gender Based Differences. In GCB - Gender and Consumer Behavior; Maclaran, P., Ed.; Association for Consumer Research: Paris, France, 2002; Volume 6, pp. 199-210.

69. Samuel, A. (Ed.) Voluntary Simplicity: The Poetic Alternative to Consumer Culture; Stead \& Daughters Ltd.: Whanganui, New Zeland, 2009; pp. 111-126, ISBN 0986453706.

70. Ballantine, P.; Arbouw, P.; Ozanne, L. Learning to Resist: The Challenges Faced by Beginner Voluntary Simplifiers. In NA-Advances in Consumer Research; Ahluwalia, R., Chartrand, T.L., Ratner, R.K., Eds.; Association for Consumer Research: Duluth, MN, USA, 2011; Volume 39, pp. 404-408. Available online: http:/ / www.acrwebsite.org/volumes/1010308/volumes/v39/NA-39 (accessed on 30 May 2018).

71. Goedkoop, M.; Heijungs, R.; Huijbregts, M.; De Schryver, A.; Struijs, J.; van Zelm, R. ReCiPe 2008. A Life Cycle Impact Assessment Method Which Comprises Harmonised Category Indicators at the Midpoint and the Endpoint Level. 2009. Available online: https://www.leidenuniv.nl/cml/ssp/publications/recipe_ characterisation.pdf (accessed on 30 May 2018).

72. Burns, A.; Burns, R. Basic Marketing Research; Pearson Education: New Jersey, NJ, USA, 2008; p. 250, ISBN 978-0-13-205958-9.

73. Allen, E.; Seaman, C. Likert scales and data analyses. Qual. Prog. 2007, 40, 64-65.

74. Fogarty, G.F. Using the Personal Orientation Inventory to measure change in student self-actualisation. Personal. Individ. Differ. 1994, 17, 435-439. [CrossRef]

75. Fitzsimons, G.J.; Hutchinson, J.W.; Williams, P.; Alba, J.W.; Chartrand, T.L.; Huber, J.; Kardes, F.R.; Menon, G.; Raghubir, P.; Russo, J.E.; et al. Non-conscious influences on consumer choice. Mark. Lett. 2002, 13, 269-279. [CrossRef]

76. Foxall, G.R. Understanding Consumer Choice; Palgrave Macmillan: New York, NY, USA, 2005. 